\title{
Diagnosis: Subcutaneous myxopapillary ependymoma
}

\section{Bashiar Thejeel $^{1} \cdot$ Ramanan Rajakulasingam ${ }^{2} \cdot$ Petra Balogh $^{3} \cdot$ Asif Saifuddin $^{2}$}

Published online: 9 March 2020

(C) ISS 2020

\section{Question:}

A 16-year-old girl presented with a 2 month history of a painless lump in the buttock.

The diagnosis can be found at https://doi.org/10.1007/s00256-02003408-w

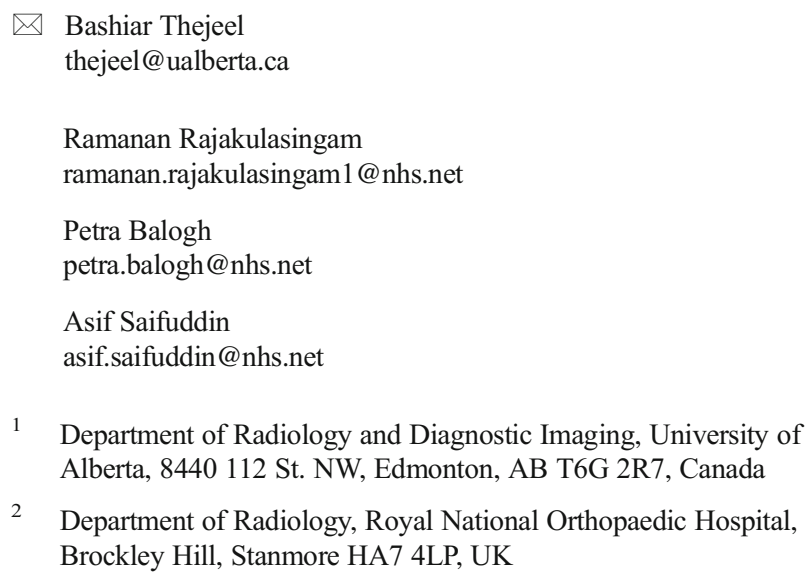

1 Department of Radiology and Diagnostic Imaging, University of Alberta, 8440112 St. NW, Edmonton, AB T6G 2R7, Canada

2 Department of Radiology, Royal National Orthopaedic Hospital, Brockley Hill, Stanmore HA7 4LP, UK

3 Department of Histopathology, Royal National Orthopaedic Hospital, Brockley Hill, Stanmore HA7 4LP, UK 

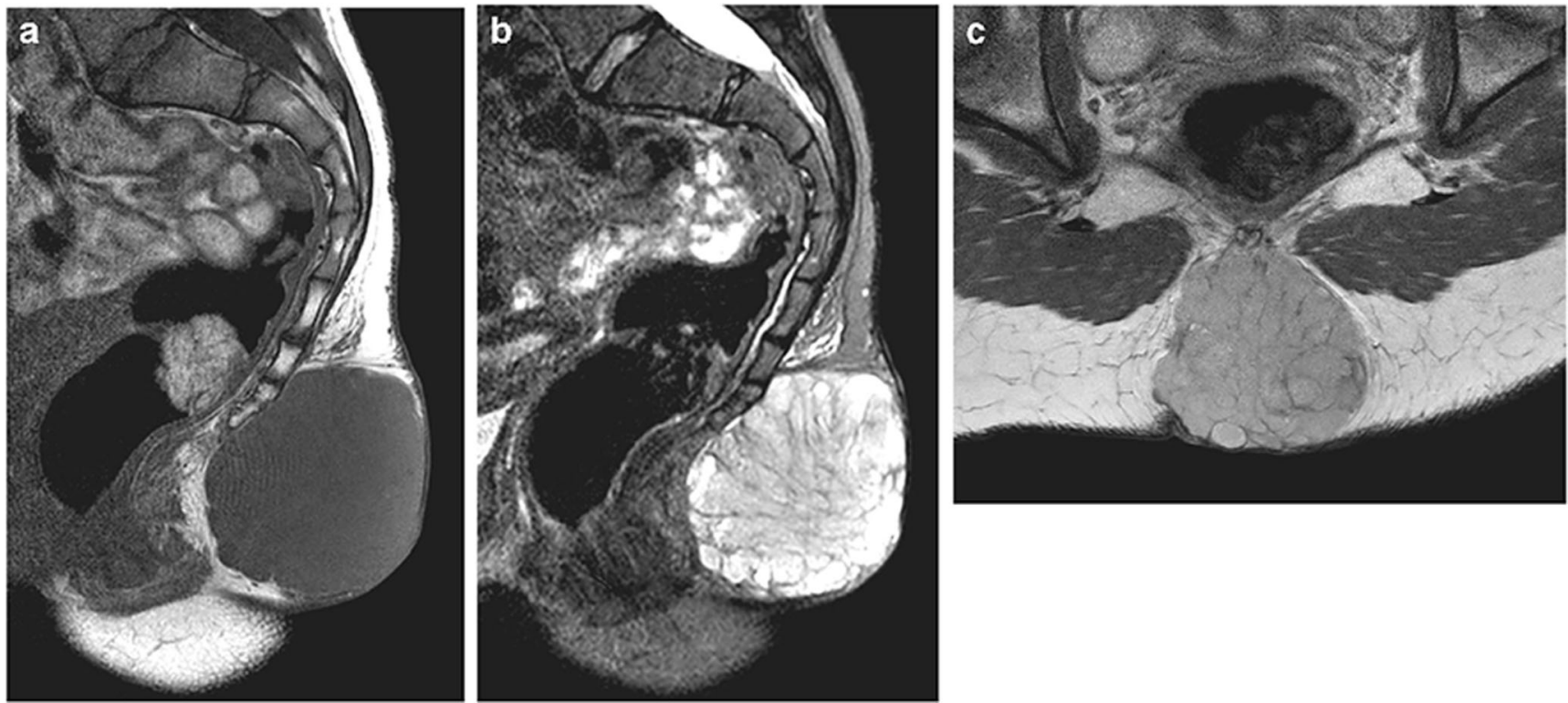

Fig. 1 a Sagittal T1W SE, (b) sagittal STIR and (c) axial PDSW FSE MR images of the sacrum
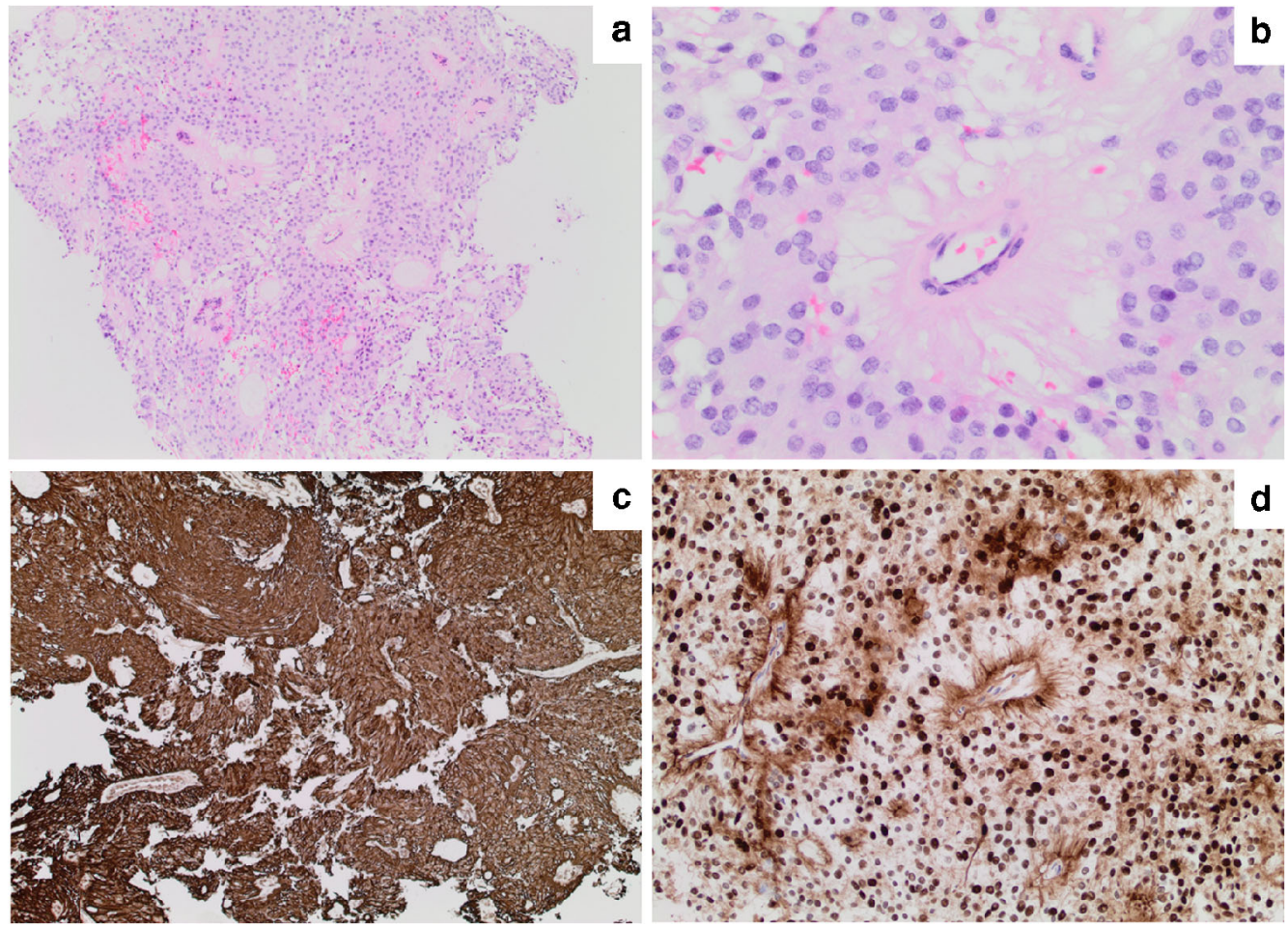

Fig. 2 a Microphotograph (H\&E, 2x magnification). b Microphotograph (H\&E, 20x magnification) (c) Immunohistochemistry for GFAP. d Immunocytochemistry for S100

Publisher's note Springer Nature remains neutral with regard to jurisdictional claims in published maps and institutional affiliations. 